Original article

\title{
A highly sensitive chemiluminescence assay for superoxide detection and chronic granulomatous disease diagnosis
}

\author{
Tsuyoshi Yamazaki ${ }^{1}$, Chikage Kawai ${ }^{2}$, Akira Yamauchi ${ }^{2}$ and Futoshi Kuribayashi ${ }^{2 *}$ \\ Received 15 March, 2011 Accepted 4 April, 2011 Published online 14 June, 2011
}

\begin{abstract}
Reactive oxygen species (ROS) produced by neutrophils are crucial for defense against infectious diseases, and the adequate measurement of ROS levels is an important way to evaluate the possibility of infections. The fluorescent probe dihydrorhodamine 123 has been applied exclusively to the measurement of ROS thus far. We developed a novel method for detecting ROS, which utilizes the chemiluminescent probes Luminol and Diogenes. The new method quantitatively detects ROS produced by as few as 10 to $10^{4}$ neutrophils. Furthermore, this method can detect ROS levels in one microliter of whole blood or ROS produced by Epstein-Barr immortalized B lymphocytes. This method will be valuable for prompt diagnosis of neonatal chronic granulomatous diseases in which neutrophils aberrantly produce superoxide.
\end{abstract}

Key words: Phagocyte NADPH oxidase, Lucigenin, Luminol, Diogenes, superoxide

\section{INTRODUCTION}

Professional phagocytes, including neutrophils, eosinophils and monocytes, play a crucial role in host defense against microbial infections [1]. During phagocytosis of invading microorganisms or upon cell stimulation with artificial activators of protein kinase $\mathrm{c}$ (PKC) such as phorbol myristate acetate (PMA), phagocytes produce superoxide, a precursor of microbicidal reactive oxygen species (ROS), by catalysis of activated phagocyte NADPH oxidase (Fig. 1 and 2) [2]. ROS derived from superoxide are essential for microbial killing. The importance of phagocyte NADPH oxidase is underlined by the genetic disorder known as chronic granulomatous disease (CGD). The neutrophils of CGD patients cannot produce superoxide, with the result that affected infants and children suffer from severe recurrent bacterial and fungal infections [3]. Catalase catalyzes toxic hydrogen peroxide to water and oxygen (Fig. 2). Thus, noncatalase producing bacteria such as Streptococcus pyogenes are not likely to become major infectious agents in CGD because they are killed by their own ROS in phagosomes. However, catalase-producing bacteria such as Staphylococcus aureus and Aspergillus fumigatus can cause lifethreatening infections in CGD patients [4].
Phagocyte NADPH oxidase is composed of a membranespanning glycoprotein, cytochrome $b_{558}$ and cytosolic proteins, $447^{\text {phox }}$, p67 $7^{\text {phox }}$, p40 $0^{\text {phox }}$, and a small G-protein, Rac [5]. Cytochrome $b_{558}$, a heterodimeric protein composed of the 91-kDa glycoprotein (gp91 $1^{\text {phox }}$ ) and the $22-\mathrm{kDa}$ protein $\left(\mathrm{p} 22^{\text {phox }}\right)$, is located in the plasma membrane of phagocytes [6]. When the cells are stimulated, cytochrome $b_{558}$ forms a complex with cytosolic proteins and is activated to produce superoxide (Fig. 1).

Superoxide produced by neutrophils can be detected by cytochrome $c$ reduction, NBT reduction, or calculated from cyanide-insensitive $\mathrm{O}_{2}$ consumption $[2,7,8]$. In recent years, the fluorescent probe dihydrorhodamine 123 (DHR) has been widely used with the flow-cytometer to quantify ROS produced by phagocytes $[9,10]$. In case of chemiluminescence (CL), Lucigenin-enhanced CL (LECL) is used because it is one of the most sensitive and convenient methods to detect reactive oxygen species (ROS) released from various cells $[11,12]$. We recently described the mechanism by which Lucigenin detects ROS [13]. LECL, however, is largely dependent upon the adhesion of neutrophils. Thus, a quantitative assay for ROS in cell suspensions is needed.

In this study, we show that a mix of the CL probes

\footnotetext{
${ }^{1}$ Department of Information and Communication Technology, School of High-Technology for Human Welfare, Tokai University, 317 Nishino, Numazu, Shizuoka 410-0395, Japan

${ }^{2}$ Department of Biochemistry, Kawasaki Medical School, Kurashiki, Okayama 701-0192, Japan

"Corresponding author:

Department of Biochemistry, Kawasaki Medical School, Kurashiki, Okayama 701-0192, Japan

Tel/Fax: $81+86$ 462-1111/1199

E-mail: kuri-f@med.kawasaki-m.ac.jp
} 


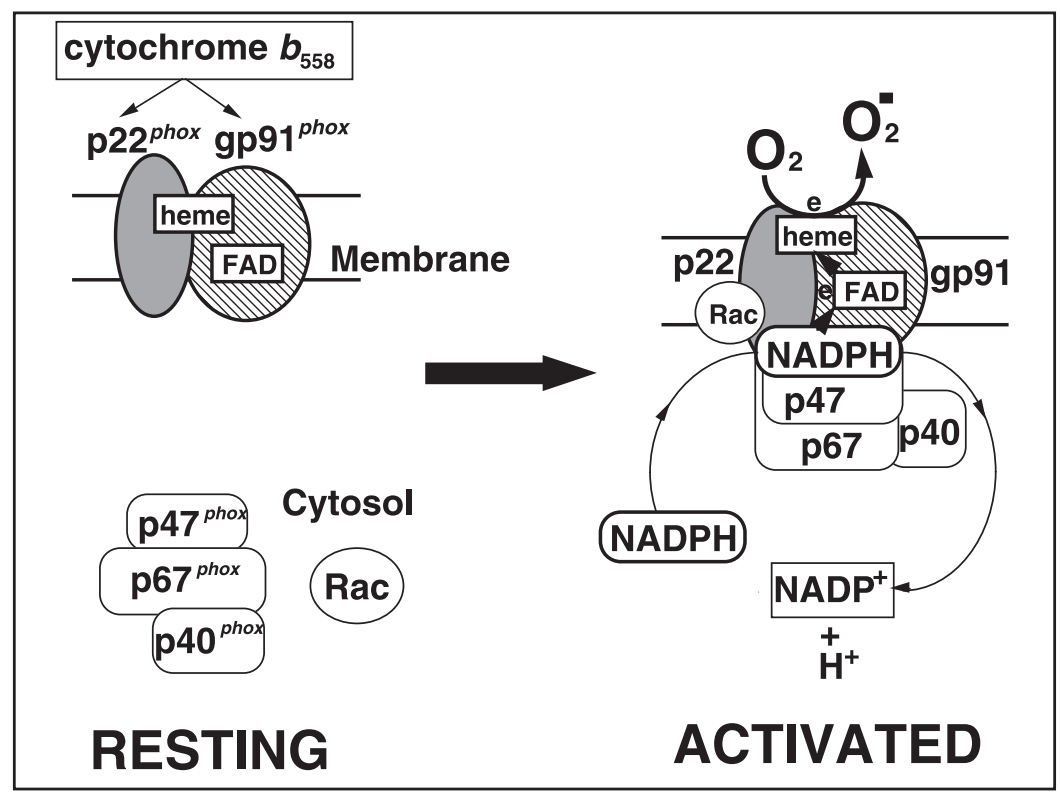

Fig. 1. Schematic representation of phagocyte NADPH oxidase. $\mathrm{p} 47^{\text {phox }}, \mathrm{p} 67^{\text {phox }}$ and $\mathrm{p} 40^{\text {phox }}$ bind each other and stay at cytosol in the "RESTING" state (left side). Upon cell stimulation by phagocytosis for bacteria, the cytosolic proteins, including small G-protein Rac, attach to membrane-bound cytochrome $b_{558}$, and the oxidase becomes "ACTIVATED" and produces superoxide anion.

$$
\begin{gathered}
\mathrm{NADPH}+2 \mathrm{O}_{2} \underset{2}{\stackrel{\text { NADPH }}{\text { oxidase }}} \longrightarrow 2 \mathrm{O}_{2}^{-}+\mathrm{NADP}^{+}+\mathrm{H}^{+} \\
2 \mathrm{H}^{+}+2 \mathrm{O}_{2}^{-} \underset{\text { Superoxide }}{\longrightarrow} \mathrm{H}_{2} \mathrm{O}_{2}+\mathrm{O}_{2} \\
2 \mathrm{H}_{2} \mathrm{O}_{2} \stackrel{\text { Catalase }}{\longrightarrow} 2 \mathrm{H}_{2} \mathrm{O}+\mathrm{O}_{2}
\end{gathered}
$$

Fig. 2. Relations between several ROS and reaction enzymes. (A) Molecular oxygen is reduced by phagocyte NADPH oxidase to produce superoxide anion. (B) Superoxide is reduced by dismutation to hydrogen peroxide and molecular oxygen. (C) Hydrogen peroxide is subjected to dismutation by catalase to become water and molecular oxygen.

Luminol and Diogenes detects ROS at a higher sensitivity than Lucigenin. Both Luminol and Diogenes are usually used alone to detect ROS, but we show that these probes work together synergistically. Detection of ROS at a high sensitivity will be useful in the clinic, where it is desirable to use only small quantities of blood to diagnose neonatal or pediatric diseases such as CGD.

\section{MATERIALS AND METHODS}

\section{Materials}

Diogenes was obtained from National Diagnostics (Atlanta, USA). 5-amino-2,3-dihydro-1,4-phthalazinedione (Luminol), bis- $N$-methylacridinium nitrate (Lucigenin), superoxide dismutase (SOD), and phorbol myristate acetate (PMA) were purchased from Sigma-Aldrich (St. Louis, USA). Dextran was obtained from GE Health Care (Piscataway, USA). Ficoll-Conray (specific gravity, 1.077) was obtained from IBL (Fujioka, Japan).

\section{Cell preparation}

Peripheral blood was collected from healthy volunteers who had given informed consent. Neutrophils were purified from the peripheral blood as previously described [14]. Briefly, the cells were isolated by a combination of dextran sedimentation, Ficoll-Conray gradient centrifugation, and hypotonic treatment. Purified neutrophils were suspended at $10^{7}$ cells $/ \mathrm{ml}$ in phosphate-buffered saline (PBS). Peripheral B lymphocytes immortalized by Epstein-Barr virus (EB-B cells) from a CGD patient and a healthy control were kindly provided by Michio Nakamura (Nagasaki University). The cells were maintained in RPMI1640 medium with 10\% fetal calf serum. 


\section{CL assay}

ROS signals were made chemiluminescent by one of the following CL probes: Lucigenin $(100 \mu \mathrm{M})$, Diogenes (100× dilution from stock solution according to the manufacturer's protocol), and/or Luminol (1 mM). For typical measurements of CL, $5 \times 10^{4}$ neutrophils were incubated in $0.3 \mathrm{ml}$ of assay buffer (PBS including $5 \mathrm{mM}$ glucose, $1 \mathrm{mM}$ $\mathrm{Mg}^{2+}, 0.5 \mathrm{mM} \mathrm{Ca}^{2+}$ and $0.05 \% \mathrm{BSA}$ ) for $3 \mathrm{~min}$ before addition of $200 \mathrm{ng} / \mathrm{ml}$ PMA. CL was monitored for $30 \mathrm{~min}$ using the automatic luminescence analyzer VARIOSKAN FLASH (Thermo Scientifc, Yokohama, Japan) or MiniLumat LB9506 (Berthold Japan, Tokyo) at $37^{\circ} \mathrm{C}$. The assay was stopped by the addition of SOD $(0.1 \mathrm{mg}(300 \mathrm{U}) / \mathrm{ml})$ to observe how the CL was detected as superoxide. Other CL protocols are described in the figure legends. For whole blood analysis, several volumes of whole blood up to $1 \mu$ were assayed in $0.3 \mathrm{ml}$ of assay buffer.

\section{RESULTS}

Diogenes mixed with Luminol achieves higher sensitivity detection of ROS than either reagent alone or Lucigenin

We have previously shown that ROS derived from adhered neutrophils, but not neutrophils in suspension are made chemiluminescent by Lucigenin [13]. Here, we compared Lucigenin with the alternative CL probes Diogenes and Luminol, alone or in combination. Neutrophils were suspended in CL probe-containing assay buffers, seeded into 96 -well plates and incubated at $37^{\circ} \mathrm{C}$ for $3 \mathrm{~min}$ prior

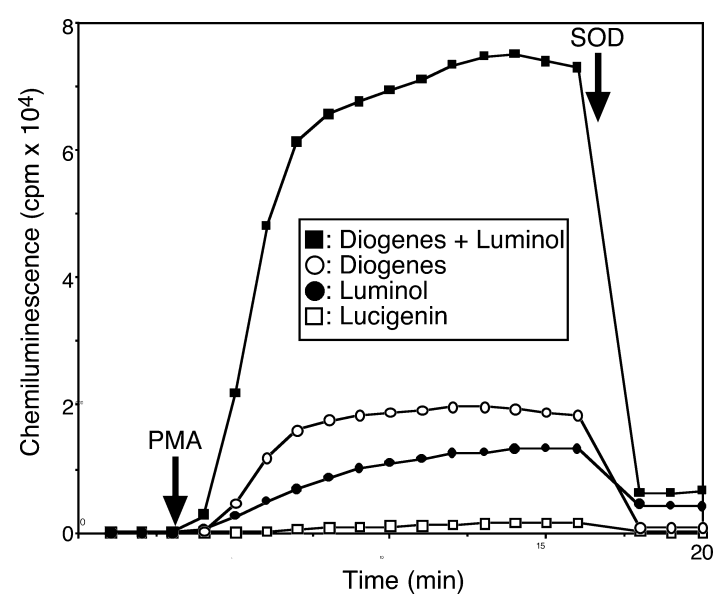

Fig. 3. Effect of Diogenes plus Luminol on CL.

Neutrophils $\left(5 \times 10^{3}\right.$ cells $)$ were preincubated with Lucigenin, Luminol, Diogenes, or Diogenes plus Luminol at $37^{\circ} \mathrm{C}$ for $3 \mathrm{~min}$ before the addition of PMA. Superoxide was eliminated by the addition of SOD $(0.1 \mathrm{mg} / \mathrm{ml})$ after $17 \mathrm{~min}$ incubation. The data are representative of results from four independent experiments.
Table 1. Maximum CL by neutrophils after PMA stimulation with four kinds of probe

\begin{aligned} & \hline Maximum cpm \\ & \hline Diogenes+Luminol: $77,536( \pm 2,533) \\ &$ Diogenes: $18,653( \pm 761) \\ &$ Luminol: $14,537( \pm 1,210) \\ &$ Lucigenin: $1,587( \pm 127) \\ &$\hline\end{aligned}

Each value is the mean ( \pm SD) obtained from four assays. Experiments are described in Fig. 3.

to PMA stimulation. CL by Diogenes with Luminol was approximately 50 times higher than that by Lucigenin (Fig. 3 and Table 1). The ratio of the PMA-stimulated CL of Diogenes with Luminol to that of assays with Diogenes and Luminol alone was approximately $4: 1$ and 5:1, respectively, indicating that Diogenes and Luminol synergistically enhance CL by ROS. PMA itself is an activator of protein kinase $\mathrm{c}$ (PKC). Thus, to confirm that the CL is dependent on ROS, we added SOD during the activation of neutrophils by PMA. CL was greatly diminished after the addition of SOD (Fig. 3), indicating that the PMA-dependent CL is due to ROS from neutrophils.

\section{Diogenes with Luminol is suitable for a quantitative assay}

Precise quantitative measurement of ROS is necessary for the diagnosis of CGD and may be prognostic for the disease. Subsequently, therefore we next examined how the CL assay with Diogenes and Luminol performs under conditions of varying numbers of ROS-producing cells. ROS released by 10 to $10^{4}$ neutrophils was proportionally detected according to cell numbers, which we propose could be useful for CGD diagnosis (Fig. 4 and Table 2).

\section{Diogenes with Luminol is a suitable reagent for the diag- nosis of CGD}

As CGD patients are typically neonates or young children, it is desirable to perform diagnostic assays with small quantities of blood. Therefore, we examined whether CL measurement assays can be performed using whole blood. Whole blood $(0.4 \mu \mathrm{l})$ in $0.3 \mathrm{ml}$ assay buffer showed significant CL after PMA addition (Fig. 5A). B lymphocytes produce superoxide at approximately $1 \%$ the rate produced by neutrophils and are often immortalized by Epstein-Barr (EB) virus for the purpose of future diagnosis. Therefore, we examined whether ROS secretion by EB-B cells can be detected using our CL assay. CL derived from control EB-B cells could be detected, but CL was not detected in CGD EB-B cells in response to PMA stimulation. These results indicated that Diogenes with Luminol was a highly sensitive reagent for ROS detection and suitable for CGD 


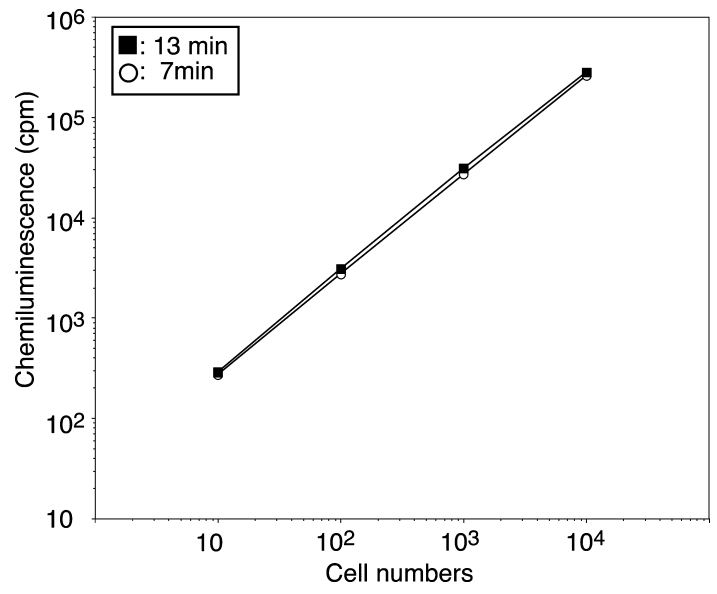

Fig. 4. Effect of cell number on Diogene and Luminol dependent CL.

Neutrophils (cell numbers indicated) were preincubated with Diogenes plus Luminol at $37^{\circ} \mathrm{C}$ for $3 \mathrm{~min}$ before the addition of PMA. CL at 7 (open circle) or 13 minutes (closed square) after PMA stimulation is shown. The data show the mean results of four independent experiments. diagnosis. Furthermore, the result using CGD cells indicated that the CL response was completely dependent on phagocyte NADPH oxidase alone and not on other enzymes responding to PMA.

\section{DISCUSSION}

In this report, we show that CL assay using a combination of Diogenes and Luminol is highly sensitive to superoxide and that the CL observed is strongly ablated by the addition of SOD. This method is approximately 50 times more sensitive than the Lucigenin-based CL assay we formerly analyzed [13]. It is still unknown how Diogenes and Luminol act synergistically to elevate CL, but it is unlikely that either reagent activates phagocyte NADPH oxidase over PMA activation, which gives the oxidase maximum activity. The two CL probes might excite each other with superoxide. Although the mechanism behhind the dramatic increase in CL using this assay remains unclear, our present results demonstrate that higher CL levels are emitted using Diogenes and Luminol in combination in reaction to the same amount of energy source, here NADPH.

Table 2. Diogenes and Luminol dependent CL at 7 and 13 min after PMA stimulation

\begin{tabular}{rcccc}
\hline & 10 & 100 & 1,000 & 10,000 (cells) \\
\hline 7 min: & $273( \pm 67)$ & $2741( \pm 437)$ & $26888( \pm 1939)$ & $260732( \pm 7426)$ \\
13 min: & $308( \pm 50)$ & $3074( \pm 519)$ & $30519( \pm 1722)$ & $281797( \pm 3114)$ \\
\hline
\end{tabular}

Each value is the mean $( \pm$ SD) obtained from four assays. Experiments are described in Fig. 4.
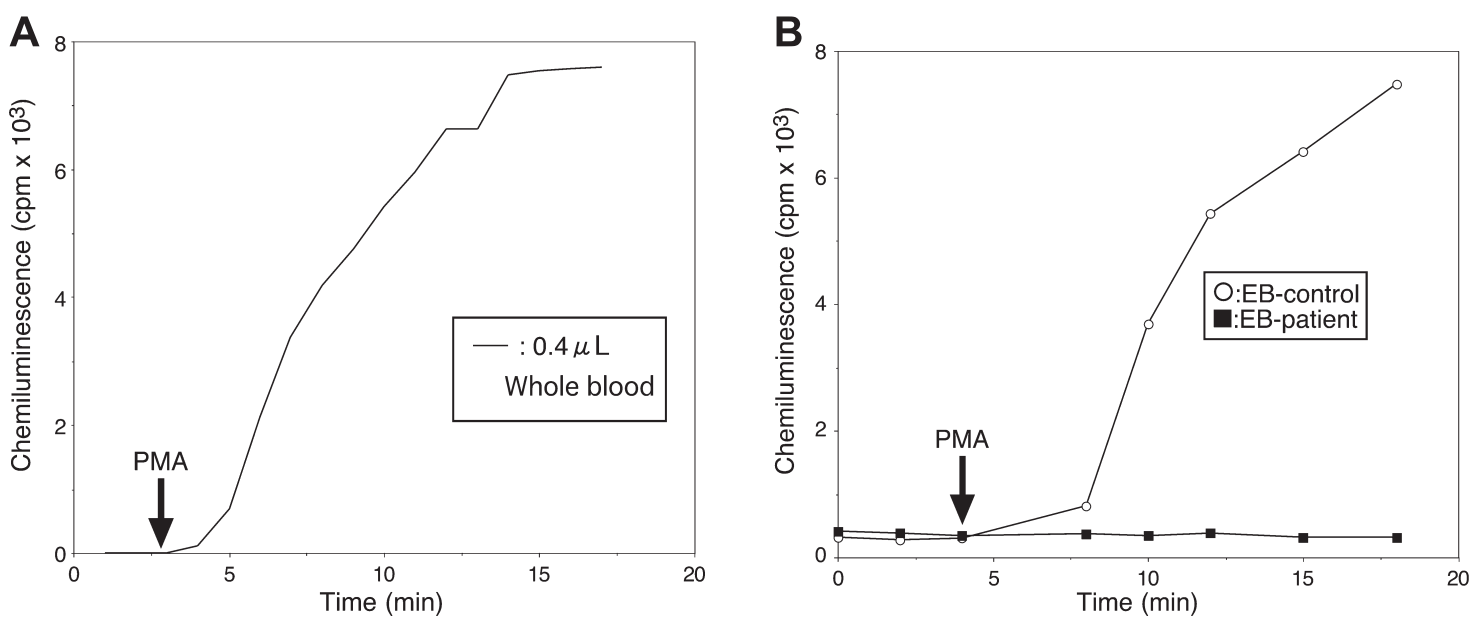

Fig. 5. Effect of whole blood or EB-B cells on Diogene and Luminol dependent CL.

Peripheral whole blood samples $(0.4 \mu \mathrm{l})$ were preincubated with Diogenes plus Luminol at $37^{\circ} \mathrm{C}$ for 3 min before the addition of PMA, and CL was followed until $17 \mathrm{~min}$. The data are representative of results from four independent experiments. (B) EB-B cells $\left(1 \times 10^{5}\right.$ cells) from a control person (open circle) and a CGD patient (closed square) were preincubated with Diogenes plus Luminol at $37^{\circ} \mathrm{C}$ for $3 \mathrm{~min}$ before the addition of PMA, and CL was followed until $18 \mathrm{~min}$. 
Lucigenin, Luminol, and Diogenes react with ROS and emit CL. The CL method is superior to other methods of ROS detection such as NBT reduction, cytochrome $c$ reduction and $\mathrm{O}_{2}$ consumption in that the $\mathrm{CL}$ probes are very sensitive to ROS. However, it remains unclear which type of ROS reacts with the CL probes. The validity of using the CL method for assaying phagocyte NADPH oxidase is demonstrated by the fact that CL by neutrophils from a control person cannot be seen without additional stimulation, such as via PMA or AMLP, and that CL cannot be detected in assays of neutrophils from CGD patients with or without stimulation.

In addition, we show that we can measure superoxide from even a small amount of whole blood by this method, which allows us to diagnose CGD in neonatal patients using a single drop of whole blood. Another method using DHR as a fluorescent probe is also highly quantitative and convenient for the detection of ROS released by activated neutrophils $[9,10]$. The method also requires just a drop of blood for diagnosis and can be applied to ROS by peripheral monocytes but not by EB-B cells.

On another front, gene therapy for CGD has just begun in clinical practice [15]. Immortalized B lymphocytes from CGD patients are stable and useful for research in gene therapy, but the weak activity of NADPH oxidase in B cells has been inconvenient. Thus, a method to detect superoxide produced by immortalized B lymphocytes from CGD patients, as we describe here, may be a useful in vitro tool for research in gene therapy as well as the diagnosis of CGD.

\section{ACKNOWLEDGMENTS}

This work was supported in part by a Grant-in-Aid for Scientific Research from the Ministry of Education, Culture, Sports, Science and Technology of Japan (21591365), a Cooperative Research Grant of the Institute of Tropical Medicine (19/20-C-2), and a Project Grant of Kawasaki Medical School (21-417).

\section{REFERENCES}

1. Kuribayashi F, Suzuki S, Nakamura M, Matsumoto T, Tsuji Y. Human peripheral eosinophils have a specific mechanism to express gp91-phox, the large subunit of cytochrome b558. Biochem Biophys Res Commun 1995; 209: $146-152$.

2. Kuribayashi F, Nunoi H, Wakamatsu K, Tsunawaki S, Sato $\mathrm{K}$, Ito T, Sumimoto $\mathrm{H}$. The adaptor protein $\mathrm{p} 40$ (phox) as a positive regulator of the superoxide-producing phagocyte oxidase. EMBO J 2002; 21: 6312-6320.

3. Roos D, de Boer M, Kuribayashi F, Meischl C, Weening RS,
Segal AW, Ahlin A, Nemet K, Hossle JP, BernatowskaMatuszkiewicz E, Middleton-Price H. Mutations in the Xlinked and autosomal recessive forms of chronic granulomatous disease. Blood 1996; 87: 1663-1681.

4. Dinauer MC, Gifford MA, Pech N, Li LL, Emshwiller P. Variable correction of host defense following gene transfer and bone marrow transplantation in murine $\mathrm{X}$-linked chronic granulomatous disease. Blood 2001; 97: 3738-3745.

5. Yamauchi A, Kim C, Li S, Marchal CC, Towe J, Atkinson SJ, Dinauer MC. Rac2-deficient murine macrophages have selective defects in superoxide production and phagocytosis of opsonized particles. J Immunol 2004; 173: 5971-5979.

6. Porter CD, Kuribayashi F, Parkar MH, Roos D, Kinnon C. Detection of gp91-phox precursor protein in B-cell lines from patients with X-linked chronic granulomatous disease as an indicator for mutations impairing cytochrome b558 biosynthesis. Biochem J 1996; 315: 571-575.

7. Baehner RL, Nathan DG. Quantitative nitroblue tetrazolium test in chronic granulomatous disease. N Engl J Med 1968; 278: 971-976.

8. Makino R, Tanaka T, Iizuka T, Ishimura Y, Kanegasaki S. Stoichiometric conversion of oxygen to superoxide anion during the respiratory burst in neutrophils. Direct evidence by a new method for measurement of superoxide anion with diacetyldeuteroheme-substituted horseradish peroxidase. J Biol Chem 1986; 261: 11444-11447.

9. Köker MY, Sanal O, De Boer M, Tezcan I, Metin A, Ersoy F, Roos D. Mutations of chronic granulomatous disease in Turkish families. Eur J Clin Invest 2007; 37: 589-595.

10. Köker MY. The evaluation of dihydrorhodamine 123 assay in chronic granulomatous disease. Pediatr Infect Dis J 2010; 29: 190-191.

11. Minkenberg I, Ferber E. Lucigenin-dependent chemiluminescence as a new assay for $\mathrm{NAD}(\mathrm{P}) \mathrm{H}$-oxidase activity in particulate fractions of human polymorphonuclear leukocytes. J Immunol Methods 1984; 71: 61-67.

12. Caldiz CI, Garciarena CD, Dulce RA, Novaretto LP, Yeves AM, Ennis IL, Cingolani HE, Chiappe de Cingolani G, Perez NG. Mitochondrial reactive oxygen species activate the slow force response to stretch in feline myocardium. $\mathrm{J}$ Physiol 2007; 584: 895-905.

13. Kuribayashi F, Tsuruta S, Yamazaki T, Nunoi H, ImajohOhmi S, Kanegasaki S, Nakamura M. Cell adhesion markedly increases lucigenin-enhanced chemiluminescence of the phagocyte NADPH oxidase. Genes Cells 2008; 13: 1249-1256.

14. Yamauchi A, Yu L, Pögens AJ, Kuribayashi F, Nunoi H, Kanegasaki S, Roos D, Malech HL, Dinauer MC, Nakamura M. Location of the epitope for 7D5, a monoclonal antibody raised against human flavocytochrome b558, to the extracellular peptide portion of primate gp91phox. Microbiol Immunol 2001; 45: 249-257.

15. Grez M, Reichenbach J, Schwäble J, Seger R, Dinauer $\mathrm{MC}$, Thrasher AJ. Gene therapy of chronic granulomatous disease: the engraftment dilemma. Mol Ther 2011; 19: 2835. 